\title{
The Effects of Self-Regulatory Learning through Computer-Assisted Intelligent Tutoring System on the Improvement of EFL Learners' Speaking Ability
}

\author{
Ahmad Mohammadzadeh \\ PhD Candidate, Urmia University, Iran, ah.mohamadzadeh64@gmail.com
}

\section{Mehdi Sarkhosh}

Asst. Prof., Urmia University, Iran, mdsarkhosh@ gmail.com

The current study attempted to investigate the effects of self-regulatory learning through computer-assisted intelligent tutoring system on the improvement of speaking ability. The participants of the study, who spoke Azeri Turkish as their mother tongue, were students of Applied Linguistics at BA level at Pars Abad's Azad University, Ardebil, Iran. According to the manual of the Oxford placement test, students who scored between 31 and 44 were considered as pre- intermediate level learners; therefore, 45 students were selected as the final participants of the present study. The participants were assigned to three groups. Groups A and B were experimental groups and received SRL through intelligent tutoring system, and group C was control group which did not receive SRL through intelligent tutoring system and instructed through traditional method. Quantitative analyses indicated that SRL through intelligent tutoring system had a significant effect on the students' improvement in the speaking skill. Results of the immediate and delayed post-tests revealed that self-monitoring strategy of SRL had a more significant effect on the students' performance in speaking than seeking-help strategy of SRL.

Keywords: intelligent tutoring system, self-regulatory learning, seeking- help, selfmonitoring, speaking

\section{INTRODUCTION}

The present study aims to investigate whether self-regulatory learning (SRL) through computer- assisted intelligent tutoring system improves performance in speaking. SRL is identified as a main prophesier of students' motivation and success, in which necessitates students to autonomously involve in planning, monitoring, and assessing their learning, and is vital to the learning process (Zimmerman, 2000). Recently, there has been much concern in studying learners' SRL strategies in computer-based learning environments 
(CBLEs) like hypermedia or inquiry learning software (Azevedo, 2008). For example, CBLEs has the function to monitor learners' observable performances while they are learning through the intelligent software. In learning through intelligent tutoring system, learners hold a conversation with autotutor in which they engage in problem-solving activities and when there is a necessity they request helping hints (Winne, 2008).

In most of the Iranian EFL contexts, students do not often monitor, regulate and evaluate their own learning process during speaking. Applying SRL to enhance speaking is particularly difficult because it postulates learners to monitor and regulate several perspectives of their learning process. To be good speakers, they need to properly utilize their phonetic knowledge and select semantically and syntactically correct forms. Besides, they ought to be able to identify and self-correct their mistakes in speaking, an ability which relates to their SRL capacity. By applying SRL in speaking, skilled speakers can promote their speaking and have fewer pauses or hesitations in their production. In traditional classes, many learners cannot decide independently of their teacher, think critically, be self-motivated, but by applying SRL, learners are more autonomous in their learning. In the present study, there is an attempt to investigate the effectiveness of seeking-help and self-monitoring strategies of SRL through intelligent tutoring system in improving speaking. Therefore, the following hypothesis is formulated: H0: Applying Self-Regulatory Learning through Intelligent Tutoring System does not Improve the Speaking of Iranian Pre-Intermediate EFL Learners.

\section{CONTEXT AND REVIEW OF LITERATURE}

\section{Theoretical Framework}

Self-regulatory learning entails well comprehending of a concept or approach by applying certain strategies and goals, monitoring and regulating specific perspectives of cognition, performance, and stimulus and also correcting behavior to attain the favourite goals (Zimmerman \& Schunk, 2001). Zimmerman (2008) viewed self-regulatory learning (SRL) as including such processes as goal setting, planning strategically, choosing and using strategies, self-monitoring and self-assessment while engaging in learning process. Zimmerman (2000, p.66) states that "SRL engages students' active participation in learning from the metacognitive, motivational and behavioral points of view."

Recently researchers have been studying the effects of SRL through intelligent tutoring system on English learning. SRL through intelligent tutoring system presents tutorial help as students learn a difficult cognitive ability (Koedinger \& Aleven, 2007). It is revealed that SRL plays a main role in learning through intelligent tutoring systems (Koedinger, Aleven, Roll, \& Baker, 2009). Instances of efficient SRL strategies that students engage while learning in these settings are whether to seek-help in completing the task (Aleven, Stahl, Schworm, Fischer, \&Wallace, 2003), whether to apply regularities in the software to solve the problem (Baker, Walonoski, Heffernan, Roll, Corbett, \& Koedinger, 2008), whether to autonomously self-explain concepts without support of software hints (Shih, Koedinger, \& Scheines, 2008), and whether to be ontask or involve in off-task behavior (Baker, 2007). Intelligent tutoring systems, like 
autotutor, ask the students deep questions and assist them give an appropriate response (Graesser, 2010).

Two main strategies of SRL such as 1) Seeking-help, and 2) Self-monitoring can help learners to be successful SRL learners. In seeking-help strategy, instructors encourage seeking-help behaviours by giving feedback to the students' progress and giving them opportunities to correct their errors. In self-monitoring strategy, in order to be active learners, students suppose ownership for their learning process in which they monitor their own learning process (Kistner, Rakoczy, \& Otto, 2010).

\section{Empirical Studies}

Kizilcec, Perez-Sanagustin, and Maldonado (2016) conducted a study on how SRL strategies would predict learner performance and goal attainment in Massive Open Online Courses. Results of their study revealed that goal setting and strategic planning predicted attainment of personal course goals, while seeking-help was counterproductive. In another study which was conducted by Jarvela (2016) on how SRL can advance computer supported collaborative learning, she explained that difficulty of SRL at the individual level, would affect learners when interacting with peers and in groups. Results of her study revealed that SRL can be both learned and also often supported with SRL tools and environments. In a study by Graesser and his colleagues $(1998,1999)$, in the tutoring research group (TRG) at the Memphis University, they invented a computerized intelligent tutor, called autotutor that simulated a natural human tutor. Autotutor tries to understand learner's contributions and simulate conversation turns of natural human tutors. In line with Grasser's research, another study was conducted by Kim and Baylor (2006) on investigating the role of intelligent tutoring system and its peer agent on students' learning. Learners with competent peer agents learned effectively, but learners with less competent peer agents presented much self-efficacy. In contrast to Kim and Baylor's views, in another study, Chi and his colleagues (2001) focused on natural conversation between learners and intelligent tutor. They believed that learners would learn much if they can declare their descriptions in natural language. The present study is an attempt to add to the existing literature on self-regulatory learning through intelligent tutoring system on the improvement of speaking among EFL students.

\section{METHOD}

\section{Design}

The current study utilizes a mixed method, quasi-experimental, pre-test, post-test design. The placement test, pre-test, immediate post-test and delayed post-test comprise the quantitative sections of the study and the questionnaire administered after the delayed post-test constitutes the qualitative section. The study consisted of one independent variable (teaching speaking) and one dependent variable (scores on IELTS speaking test). The participants were assigned to three groups: group A, which received seekinghelp strategy of SRL through intelligent tutoring system and group B, which received self-monitoring strategy of SRL through intelligent tutoring system, and group C (control group), which did not receive SRL through intelligent tutoring system. 


\section{Participants}

The number of the participants for the current study was 100 (male=39; female=61) English students studying at Azad University of Pars Abad, Ardebil, Iran. They all spoke Azeri Turkish as their mother tongue and were students of Applied Linguistics at BA level. The researchers gave them a placement test in order to confirm their homogeneity. According to the manual of the Oxford placement test, students who scored between 31 and 44 were considered as pre- intermediate level learners; therefore, 45 students were selected as the final participants of the present study. The average age of the participants was 24 , ranging from 18 to 27 .

\section{Instruments}

A) Oxford Placement Test: It was run to measure the participants' English proficiency. It consists of three sections. Total score is 70 and students answered the test in 120 minutes.

B) IELTS Speaking Test (pre-test, immediate post-test, delayed post-test): Students were asked to respond orally to the questions of IELTS speaking test, and their voices were recorded. IELTS speaking section consists of three sections and takes 20 minutes.

C) The Questionnaire (Researcher Designed): There were 21 questions about learning through computer-assisted intelligent tutoring system. Students were asked to show their beliefs about the statements of the questionary on a Likert Scale with five answers ranging from very much to not at all. There were also two open ended questions in which students were asked to explain their attitudes toward learning through intelligent tutoring system.

D) Autotutor Software: ITS has a five-step conversation frame, which is one of the main conversation models in natural speech tutoring (Graesser \& Person, 1994). Autotutor acts as a teacher and student, every time, can refer to the autotutor and ask for help.

\section{Procedure}

\section{Treatment and Data Collection}

Students used intelligent tutoring system (software) to speak with autotutor for practicing in speaking. By displaying this part (see Figure 1), students were able to start speaking.

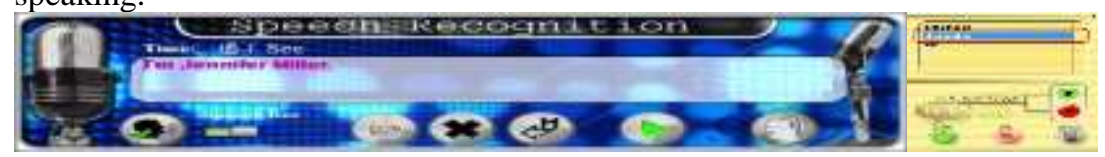

Figure 1

Speech recognition icon

After watching the video file, autotutor let students speak instead of movie characters.

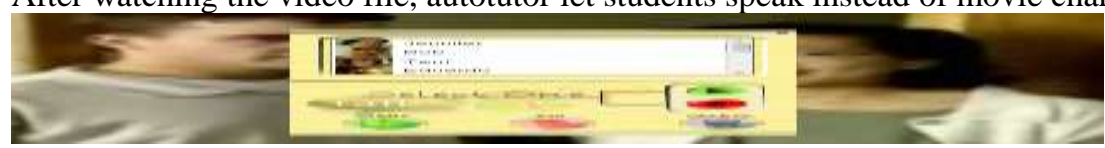

Figure 2

Movie section icon 
Another application of the intelligent tutoring system is that after recording student's voice, it drew diagram of the speaker's pronunciation (See Figure 3).

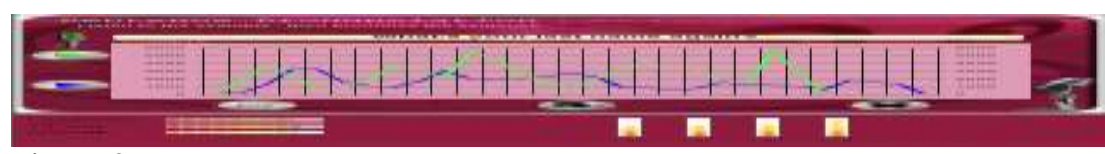

Figure 3

Pronunciation diagram icon

Two strategies of SRL were applied in this study. Group A received seeking-help strategy, and group B received self-monitoring strategy, and group $\mathrm{C}$ received the traditional method of teaching speaking. The students of group A were able to ask for help from the autotutor to correct their mistakes in speaking. Autotutor displayed the correct answers of the speaking task and then students had to complete the task again until they could complete the task correctly. There were intelligent tutorial dialogs between the students and the autotutor. In seeking-help strategy, learners did not try to complete every task by themselves, but often were seeking help from intelligent autotutor when there was a problem in their learning process. Students of group B applied self-monitoring strategy in which they rarely referred to the autotutor's hints and prompts to complete the answers. They tried to self-correct their errors and be more selfregulated and autonomous learners. For example, in movie section, a student, once or several times, watches a movie file, takes notes and then starts to speak instead of movie characters and repeats this training until he/she completes the task correctly. In selfmonitoring strategy, students did not use autotutor's helping hints frequently and only when there was a necessity, they referred to the autotutor's hints and guidance. Group C was the control group and did not receive SRL via intelligent tutoring system in speaking. Speaking was taught in accordance with the traditional method in Iran. The current study lasted for 13 sessions from February to May during the second semester of 2016. Each group consisted of 15 participants. In the first session, students were asked to answer the pre-test and from the next session, they received treatment. Treatment lasted for ten sessions. In the 12th session, students received the immediate post-test. After a month students received the delayed post- test.

\section{Scoring}

The scorers applied the analytic scoring technique with 4 scoring criteria, namely, fluency \& coherence, pronunciation, lexical resource, and grammatical range \& accuracy. According to IELTS Band Descriptor Scoring, the 4 criteria are assessed on a 10 -point scale ranging from 0 to 9 with appropriate descriptions.

\section{Data Analysis}

SPSS version 22 was used to analyse the data. In order to confirm the normality of the scores, One-Sample Kolmogorov-Smirnov test was run. Kruskal-Wallis test was run to determine if there were statistically significant differences between the groups. A Repeated Measures ANOVA was run to investigate if there were any significant gains from pre-test to immediate to delayed post-tests. 


\section{FINDINGS}

\section{Quantitative Analysis}

Below, the descriptive statistics regarding the four tests of placement test, pre-test, immediate post-test and delayed post-test is provided (see Table 1).

Table 1

Descriptive statistics for groups' performances in the placement test, pre-test, immediate post-test and delayed post-test

\begin{tabular}{lllllll}
\hline Tests & Groups & $\mathrm{N}$ & Minimum & Maximum & Mean & Std. Deviation \\
\hline \multirow{3}{*}{ Placement } & $\mathrm{A}$ & 15 & 37.25 & 39.50 & 38.16 & 0.75 \\
& $\mathrm{~B}$ & 15 & 36.75 & 40.00 & 38.45 & 0.96 \\
& $\mathrm{C}$ & 15 & 37.50 & 41.00 & 38.86 & 1.04 \\
\hline \multirow{3}{*}{ Pre-test } & $\mathrm{A}$ & 15 & 3.75 & 6.00 & 4.68 & 0.67 \\
& $\mathrm{~B}$ & 15 & 4.00 & 5.50 & 4.58 & 0.41 \\
& $\mathrm{C}$ & 15 & 3.50 & 5.00 & 4.75 & 0.37 \\
Immediate & $\mathrm{A}$ & 15 & 4.25 & 6.50 & 5.18 & 0.60 \\
Post-test & $\mathrm{C}$ & 15 & 4.75 & 6.50 & 5.53 & 0.43 \\
\hline \multirow{3}{*}{ Delayed } & $\mathrm{A}$ & 15 & 3.75 & 5.25 & 4.83 & 0.33 \\
Post-test & $\mathrm{B}$ & 15 & 4.25 & 6.50 & 4.96 & 0.60 \\
\hline Note: A & CR & 15 & 4.50 & 6.00 & 5.36 & 0.41 \\
\hline
\end{tabular}

Note: A= SRL (Seeking- help); B= SRL (Self-monitoring); $\mathrm{C}=$ Traditional

In order to determine the normality of the scores, the researchers used One-Sample Kolmogorov-Smirnov (K-S) test. The result of the K-S Test (Table 2) indicated that the normality assumption was not violated in the majority of cases. As table two reveals, regarding the placement test, the groups were normal (sig $>0.05$ ). However, concerning the pre-test and post-test scores, the scores in group $\mathrm{C}$ did not enjoy normal distribution $(\operatorname{sig}<0.05)$. Therefore, for comparing the groups in terms of placement, parametric tests and in comparing groups at pre-test and post-tests, non-parametric tests were run.

Table 2

Normality tests for placement test, pre-test, immediate post-test and delayed post-test

\begin{tabular}{llll}
\hline & Groups & Statistic & Sig. \\
\hline \multirow{3}{*}{ Placement } & A & 0.181 & 0.164 \\
& B & 0.121 & 0.200 \\
\multirow{3}{*}{ Pre-test } & C & 0.170 & 0.200 \\
\hline \multirow{2}{*}{ Immediate Post-test } & A & 0.141 & 0.200 \\
& B & 0.187 & 0.168 \\
& C & 0.367 & 0.000 \\
\hline \multirow{2}{*}{ Delayed Post-test } & A & 0.165 & 0.200 \\
& B & 0.197 & 0.120 \\
& C & 0.335 & 0.000 \\
\hline
\end{tabular}

Note: A= SRL (Seeking- help); B= SRL (Self-monitoring); $\mathrm{C}=$ Traditional 
Table 3

Ranks for the pre-test, immediate post-test and delayed post- test

\begin{tabular}{llll}
\hline & Groups & N & Mean Rank \\
\hline \multirow{3}{*}{ Pre-test } & A & 15 & 22.70 \\
& B & 15 & 19.67 \\
& C & 15 & 26.63 \\
\hline \multirow{3}{*}{ Immediate Post-test } & A & 15 & 22.80 \\
& B & 15 & 32.20 \\
Delayed Post-test & C & 15 & 14.00 \\
& A & 15 & 21.97 \\
& B & 15 & 33.00 \\
\hline
\end{tabular}

Note: A= SRL (Seeking- help); B= SRL (Self-monitoring); $\mathrm{C}=$ Traditional

Table 4

Kruskal-Wallis test for the three groups at pre-test, immediate post-test and delayed post-test

\begin{tabular}{lccc}
\hline & Pre-test & Immediate Post-test & Delayed Post-test \\
\hline Chi-square & 2.18 & 14.81 & 16.11 \\
\hline df & 2 & 2 & 2 \\
\hline Asymp.sig. & 0.33 & 0.00 & 0.0000 \\
\hline
\end{tabular}

Table three reveals that the three groups performed differently at pre-test and post-tests. At pre-test, the control group had the highest and the self-monitoring group had the lowest mean score; however, according to table four, the difference was not significant (sig>0.05). At the immediate post-test, the self-monitoring group had the highest mean score and the seeking-help was the second highest. The difference between the three groups, according to table four, was significant $(\operatorname{sig}<0.05)$. At the delayed post-test, also, the self-monitoring group had the highest mean score and the seeking-help was the second highest with the difference between groups being significant $(\operatorname{sig}<0.05)$.

\section{Repeated Measures (Within Subjects) ANOVA}

Since the same participants in each group took the same test three times (pre-test, immediate post-test and delayed post-test), a Repeated Measures (RM) ANOVA was run in order to find out if there was any gains or improvement from pre-test to immediate to delayed post-tests. Table five and six show the three occasions at which the tests were administered.

Table 5

Measures

\begin{tabular}{cl}
\hline Time & Dependent Variable \\
\hline 1 & Pre-test \\
2 & Immediate Post-test \\
3 & Delayed Post-test \\
\hline
\end{tabular}


Table 6

Descriptive statistics

\begin{tabular}{lllllcll}
\hline & \multicolumn{3}{l}{ Seeking-help } & \multicolumn{3}{l}{ Self-monitoring } & Traditional \\
\hline & $\mathrm{N}$ & Mean & $\mathrm{Sd}$ & Mean & $\mathrm{Sd}$ & Mean & $\mathrm{Sd}$ \\
\hline Pre-test & 15 & 4.68 & 0.67 & 4.58 & 0.41 & 4.75 & 0.37 \\
Immediate post-test & 15 & 5.18 & 0.60 & 5.53 & 0.43 & 4.83 & 0.33 \\
Delayed post-test & 15 & 4.96 & 0.60 & 5.36 & 0.41 & 4.61 & 0.33 \\
\hline
\end{tabular}

RM ANOVA with a Greenhouse-Geisser correction revealed that the mean performance in speaking differed statistically significantly between time points for the seeking-help group $(F(1.786,25.005)=35.737, P<0.05)$, for the self-monitoring group $(F(1.548$, $21.666)=87.233, P<0.05)$, and for the Control group $(F(1.546,21.641)=6.920, P<$ $0.05)$ (see Table 7).

Table 7

Tests of within-subjects effects

\begin{tabular}{|c|c|c|c|c|c|c|c|c|}
\hline & Source & & $\begin{array}{l}\text { Type III } \\
\text { Sum of } \\
\text { Squares }\end{array}$ & Df & $\begin{array}{l}\text { Mean } \\
\text { Square }\end{array}$ & $\mathrm{F}$ & Sig & $\begin{array}{l}\text { Partial } \\
\text { Eta } \\
\text { Squared }\end{array}$ \\
\hline \multirow[t]{4}{*}{$\begin{array}{l}\text { Seeking- } \\
\text { help }\end{array}$} & Time & $\begin{array}{l}\text { Sphericity } \\
\text { Assumed }\end{array}$ & 1.88 & 2 & 0.94 & 35.73 & 0.00 & 0.71 \\
\hline & & $\begin{array}{l}\text { Greenhouse- } \\
\text { Geiser }\end{array}$ & 1.88 & 1.78 & 1.05 & 35.73 & 0.00 & 0.71 \\
\hline & $\begin{array}{l}\text { Time } \\
\text { (error) }\end{array}$ & $\begin{array}{l}\text { Sphericity } \\
\text { Assumed }\end{array}$ & 0.73 & 28.00 & 0.02 & & & \\
\hline & & $\begin{array}{l}\text { Greenhouse- } \\
\text { Geiser }\end{array}$ & 0.73 & 25.00 & 0.03 & & & \\
\hline \multirow[t]{4}{*}{$\begin{array}{l}\text { Self- } \\
\text { monitoring }\end{array}$} & Time & $\begin{array}{l}\text { Sphericity } \\
\text { Assumed }\end{array}$ & 7.71 & 2 & 3.86 & 87.23 & .000 & 0.86 \\
\hline & & $\begin{array}{l}\text { Greenhouse- } \\
\text { Geiser }\end{array}$ & 7.71 & 1.54 & 4.98 & 87.23 & .000 & 0.86 \\
\hline & $\begin{array}{l}\text { Time } \\
\text { (error) }\end{array}$ & $\begin{array}{l}\text { Sphericity } \\
\text { Assumed }\end{array}$ & 1.239 & 28 & 0.044 & & & \\
\hline & & $\begin{array}{l}\text { Greenhouse- } \\
\text { Geiser }\end{array}$ & 1.239 & 21.666 & 0.057 & & & \\
\hline \multirow[t]{4}{*}{ Control } & Time & $\begin{array}{l}\text { Sphericity } \\
\text { Assumed }\end{array}$ & 0.35 & 2 & 0.17 & 6.92 & .004 & 0.33 \\
\hline & & $\begin{array}{l}\text { Greenhouse- } \\
\text { Geiser }\end{array}$ & 0.35 & 1.54 & 0.23 & 6.92 & .008 & 0.33 \\
\hline & $\begin{array}{l}\text { Time } \\
\text { (error) }\end{array}$ & $\begin{array}{l}\text { Sphericity } \\
\text { Assumed }\end{array}$ & 0.72 & 28 & 0.26 & & & \\
\hline & & $\begin{array}{l}\text { Greenhouse- } \\
\text { Geiser }\end{array}$ & 0.72 & 21.64 & 0.34 & & & \\
\hline
\end{tabular}

Post-hoc tests using the Bonferroni correction (Table 8) showed that seeking-help strategy improved speaking from pre-test to the immediate post-test and also from pretest to the delayed post-test $(\operatorname{sig}<0.05)$. Although the mean score declined from the immediate post-test to the delayed post-test, it was still significantly higher compared to the pre-test. Therefore, seeking-help strategy improves speaking both in the short-run 
and the long-run. Post-hoc tests also showed that self-monitoring strategy improved speaking from pre-test to the immediate post-test and also from pre-test to the delayed post-test $(\operatorname{sig}<0.05)$. Therefore, it can be concluded that self-monitoring strategy improves speaking both in the short and the long-run. Post-hoc tests using the Bonferroni correction divulged that the traditional teaching of speaking did not improve speaking from pre-test to the immediate post-test or delayed post-test ( $\operatorname{sig}>0.05)$.

Table 8

Pairwise comparisons

\begin{tabular}{|c|c|c|c|c|c|c|c|}
\hline & \multicolumn{7}{|c|}{ 95\% Confidence Interval for Difference } \\
\hline & (I) & $(\mathrm{J})$ & $(\mathrm{I}-\mathrm{J})$ & Std. & Sig. & Lower & Upper \\
\hline & Time & Time & Mean & Error & & Bound & Bound \\
\hline \multirow{6}{*}{$\begin{array}{l}\text { Seeking- } \\
\text { help }\end{array}$} & \multirow[t]{2}{*}{1} & 2 & $-0.500^{*}$ & 0.065 & 0.000 & -0.675 & -0.325 \\
\hline & & 3 & $-0.283 *$ & 0.064 & 0.002 & -0.457 & -0.110 \\
\hline & \multirow[t]{2}{*}{2} & 1 & $0.500 *$ & 0.065 & 0.000 & 0.325 & 0.675 \\
\hline & & 3 & $0.217 *$ & 0.048 & 0.001 & 0.325 & 0.347 \\
\hline & \multirow[t]{2}{*}{3} & 1 & $0.283^{*}$ & 0.064 & 0.002 & 0.110 & 0.457 \\
\hline & & 2 & $-0.217 *$ & 0.048 & 0.001 & -0.437 & -0.086 \\
\hline \multirow{6}{*}{$\begin{array}{l}\text { Self- } \\
\text { monitoring }\end{array}$} & \multirow[t]{2}{*}{1} & 2 & $-0.950^{*}$ & 0.074 & 0.000 & -1.151 & -0.749 \\
\hline & & 3 & $-0.783^{*}$ & 0.094 & 0.000 & -1.039 & -0.528 \\
\hline & \multirow[t]{2}{*}{2} & 1 & $0.950^{*}$ & 0.074 & 0.000 & 0.749 & 1.151 \\
\hline & & 3 & $0.167 *$ & 0.058 & 0.037 & 0.009 & 0.325 \\
\hline & \multirow[t]{2}{*}{3} & 1 & $0.783^{*}$ & 0.094 & 0.000 & -0.528 & 1.039 \\
\hline & & 2 & $-0.167^{*}$ & 0.058 & 0.037 & -0.325 & -0.009 \\
\hline \multirow[t]{6}{*}{ Control } & \multirow[t]{2}{*}{1} & 2 & -0.083 & 0.047 & 0.288 & -0.210 & 0.044 \\
\hline & & 3 & 0.133 & 0.073 & 0.263 & -0.064 & 0.331 \\
\hline & \multirow[t]{2}{*}{2} & 1 & 0.083 & 0.047 & 0.288 & -0.044 & 0.210 \\
\hline & & 3 & $0.217^{*}$ & 0.054 & 0.004 & 0.070 & 0.363 \\
\hline & \multirow[t]{2}{*}{3} & 1 & -0.133 & 0.073 & 0.263 & -0.331 & 0.064 \\
\hline & & 2 & $-0.217^{*}$ & 0.054 & 0.004 & 0.363 & -0.070 \\
\hline
\end{tabular}

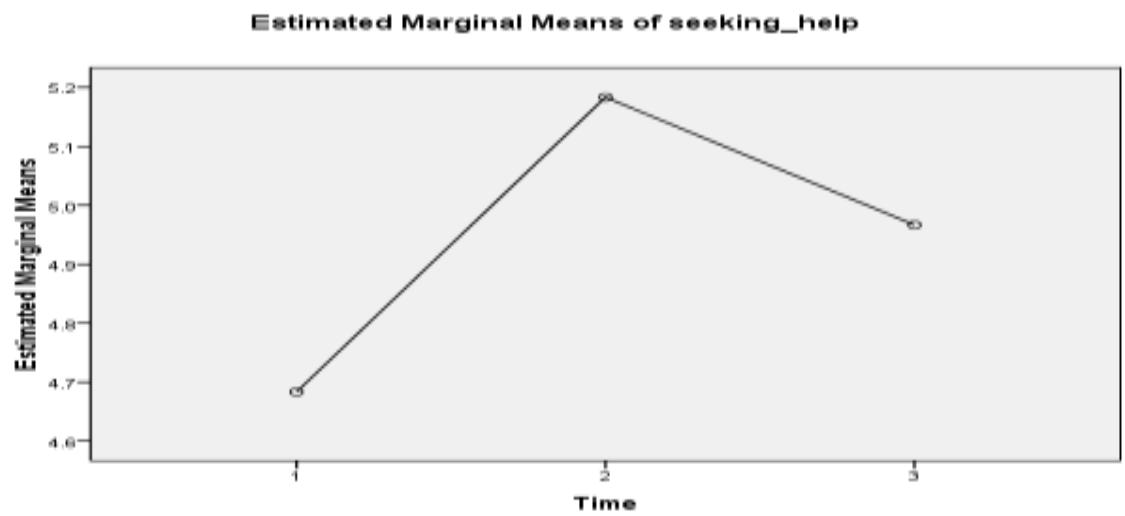

Figure 4

Speaking mean score on the three testing occasions in the seeking-help group 


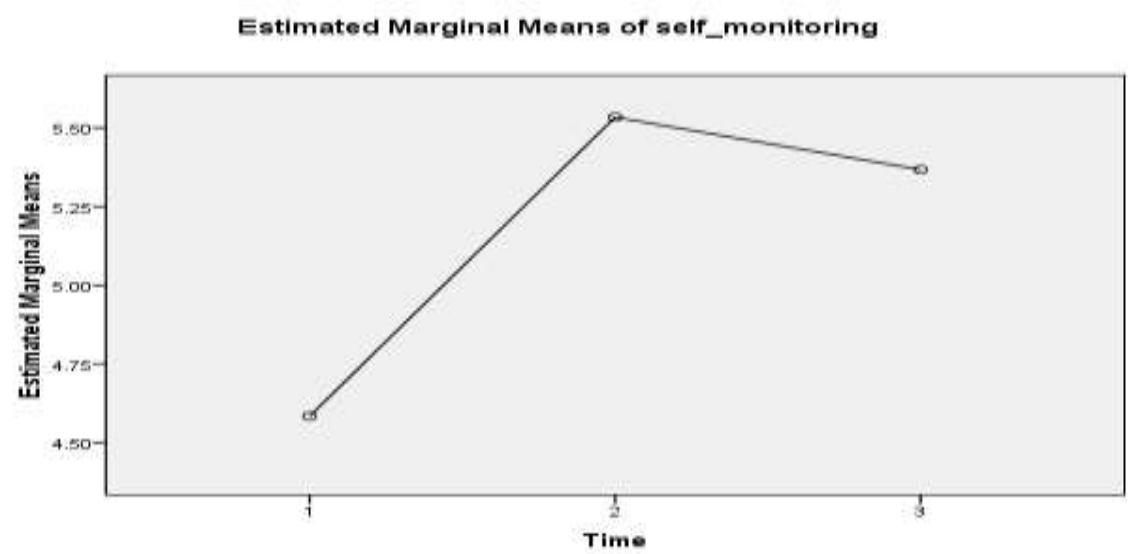

Figure 5

Speaking mean score on the three testing occasions in the self-monitoring group

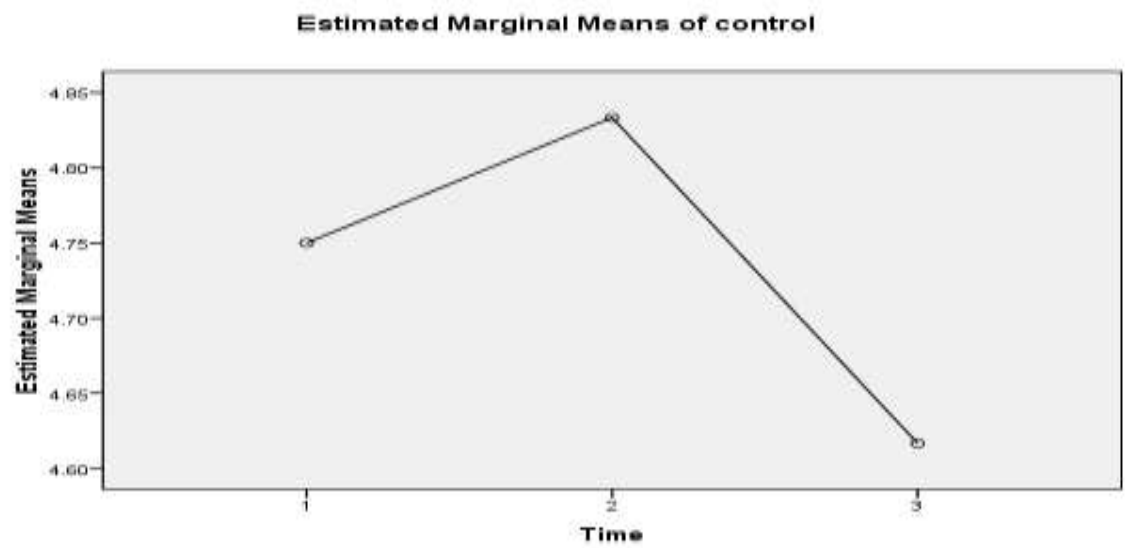

Figure 6

Speaking mean score on the three testing occasions in the traditional group

\section{Qualitative Analysis (the questionnaire)}

Analysis of the questionnaire indicated that, most of the learners had not much experience in applying computer-assisted learning in their education. Majority of the students $(85 \%)$ asserted that they were not familiar with the electronic educational tools in their education (Q.1). About $87 \%$ of the students reported that they had no experience or had very little experience with learning through computer (Q.2). About $68 \%$ of the students reported that computer-assisted learning could not replace lectures and exercises in their learning process (Q.3). About $65 \%$ of the students believed that 
computer-assisted learning should be used only to supplement classroom lectures and exercises and it is effective for their learning (Q.4). Some of the students (30\%) expressed that they had difficulties applying learning programs that were in English (Q.5). Most of the students (82\%) expressed that the intelligent tutoring system was enjoyable and very easy to use (Q.6, Q.7). About $10 \%$ of the students believed that applying navigational tools were confusing in their learning process (Q.8). A few students $(17 \%)$ expressed that intelligent tutoring system should be nothing more than the distribution of notes and tutorial comments (Q.9). Most of the students (90\%) expressed that they had not significant technical problems during learning through intelligent tutoring system (Q.10, Q.11). About $87 \%$ of the students believed that the learning goal, outcomes, objectives and expectations for the course taught by the intelligent tutoring system were clearly stated and the offered course met the stated learning goal, outcome and objective (Q.12, Q.13).

About $90 \%$ of the students expressed that the course content was well organized (Q.14). Some of the students $(30 \%)$ believed that the amount of content was not suitable for the length of the course in their learning process (Q.15). About $27 \%$ of the students asserted that the content of the course was too difficult for them (Q.16). About $75 \%$ of the students reported that the helpful examples of lessons were useful for improving their learning process (Q.17). About $70 \%$ of the students expressed that they were encouraged to take responsibility for their own learning (Q.18). About $85 \%$ of the students expressed that during the course, most of them usually had a clear idea of where they were going and what was expected from them (Q.19). About 29\% of the students expressed that they were not given enough choices over how they were going to learn in the course (Q.20). Most of the students (88\%) expressed that they had learned a lot about design patterns from the intelligent tutoring system (Q.21).

Analysis of open-ended questions (Q.22, Q.23) revealed that most of the students had positive attitudes toward the course, and they mentioned the course content well organization and easy access to the multimedia content as the main benefits of learning through intelligent tutoring system. Students also reported some shortcomings of learning through intelligent tutoring system, which were mainly associated to the technical problems, and no application of cooperative learning.

\section{DISCUSSION}

The main aim of the current study was to investigate the effects of SRL via computerassisted intelligent tutoring system on improving speaking ability among Iranian EFL learners. The quantitative analyses indicated that SRL had a significant effect on improving the participants' speaking. The findings revealed that the participants in the experimental groups made significant improvements, which appears to have resulted from the SRL intervention. A series of One-Way ANOVA's revealed that there were no differences between the three groups at the placement test or the pre-test. However, at the immediate post-test and delayed post-test, significant differences between the groups were observed. The results of this study indicated that the students of both seeking-help group and self-monitoring group performed significantly at both the immediate post-test and delayed post-test compared to the traditional group. Therefore, it can be concluded 
that both seeking-help and self-monitoring strategies of SRL improve speaking better than the traditional method. A series of RM ANOVA's also indicated that the participants in the seeking-help group improved significantly from pre-test to the immediate post-test and also from pre-test to the delayed post-test, which means that seeking-help strategy ameliorated the participants' performance in speaking both in the short-run and the long-run. In the self-monitoring group, likewise, the performance of the participants improved significantly from pre-test to the immediate post-test and also from pre-test to the delayed post-test, which means that self-monitoring strategy improves performance in speaking both in the short-run and in the long-run. Regarding the traditional group, there was no significant gain from pre-test to the immediate posttest, nor was there a gain from pre-test to the delayed post-test, which implies that the traditional teaching of speaking, in Iran, does not yield any significant short-term or long-term improvement in speaking. Qualitative analysis also indicated students of experimental groups satisfied and profited a lot from instructing through intelligent tutoring system and thus promoted in their speaking ability.

In general results of the current study seem to verify the approach that SRL associates to the improvement of learners' emotions and feelings. Since SRL involves different strategies that students apply to manage their tasks, emotions and, it associates positively to the increasing of their self-esteem, for instance, in self-monitoring strategy, students were able to self-evaluate their speaking and were able to control their negative emotions. Since SRL students can regulate their attempt and strategies in order to perform their activity and reach to their goals, they recognize when to insist, when to seek for help, and how to achieve the task. This appears to have resulted to the significant promotion in learners' speaking ability. This is to say that applying SRL approach has a significant effect on students' enhancement in speaking skill, but the traditional approach of teaching speaking has not a significant effect on students' enhancement in speaking skill. Contrary to the popular belief, SRL students do not attempt to complete every task by themselves, but rather often ask help from others when there is a necessity (Butler, 1998). The distinction between SRL students and other students is that they seek help from others with the aim of becoming more independent learners (Ryan, Pintrich, \& Midgley, 2001).

Graesser and McNamara (2010), in their article, discussed the integration of SRL with human tutor and computer tutor. They reported that computer tutoring had a positive effect on learners' enhancement in which the agents hold conversation with learners and assist them learn through modelling good pedagogy and learning processes or by holding an active conversation. Their study is in line with the findings of the current research in which applying intelligent tutoring system and SRL strategies enhanced learning. In another study on designing learning by intelligent agents by Leelawong and Biswas (2008), the students used SRL strategies and requested their agent to monitor their learning and problem solving activity. This method is similar to seeking-help strategy of SRL. Their results indicated that SRL via intelligent tutoring system better prepared students to learn in new domains. The findings of the present study are also in line with Kosek and Lison (2014), who conducted a study on intelligent tutoring system that enabled Chinese learners to acquire active knowledge of words and grammatical 
constructions. The results of their study suggested that the cognitive system improved students' learning process. Their method is akin to seeking-help strategy of learners in which students requested intelligent tutoring system to monitor their learning procedure. In a study by D'Mello and Graesser (2012), on learning by talking with cognitively and emotionally intelligent system, autotutor helped students to deal with critical thinking by holding conversation with autotutor in natural speech with adaptive conversation turns like natural human tutoring. Students regulated their learning and were more autonomous learners in solving problems. Their study supports the current study in terms of the issue that applying SRL through intelligent tutoring system improves students' speaking.

Learning speaking skill by applying SRL through intelligent tutoring system is an efficient method in the Iranian context than learning speaking by traditional method. Since the Iranian students are far from the native context and most of their learning happens in the classrooms without any computers and intelligent tutoring systems, application of an appropriate teaching method such as SRL promotes students' speaking ability. Taught through the traditional method in speaking, students didn't promote in their speaking significantly where they only were listeners and didn't have active participation in class conversations. On the other hand, in SRL through intelligent tutoring system, they were more active learners and interactively participated in conversations with intelligent autotutor.

Results of the current study indicated that self-monitoring strategy had a more significant effect on students' performance in speaking than seeking-help strategy. Selfmonitoring enables learners to self-monitor and self-evaluate their knowledge during their learning process. This is associated to metacognitive knowledge monitoring in which when students are engaging in completing the task; they should be capable of monitoring their learning process. Students who are active SRL learners will use intelligent tutor's feedback in order to monitor their progress. Active students asserted that the immediate feedback presented by an intelligent autotutor caused a kind of frustration, but was also useful to their learning process. When there was a necessity they referred to the intelligent autotutor's feedbacks, and they were able to recognize their errors, and evaluate their progress. Learners who suppose that intelligence is fixed mostly have a difficulty in facing with challenges for fear of failure, whereas learners via self-monitoring strategy view challenges as chances for effective learning. According to the results, seeking-help strategy had a lesser effect on students' speaking than selfmonitoring strategy. Students of seeking-help group improved their speaking with intelligent autotutor's help seeking mechanism while these mechanisms assist students regulate their own learning procedure; it is up to the learners to decide whether to benefit from these strategies. Seeking-help mechanism initiates help when the student struggles and advices the level of help for student. The learner still has the right to choose - for example, the student can ignore the received feedback or can ask for more help (Aleven, Stahl, Schworm, Fischer, \&Wallace, 2003).

The intelligent autotutor also offers the level of help to use during completing the task by students. However, instead of providing the help to the student, the intelligent 
autotutor just offers the student on the extent of help, and the final decision is left to the student (Roll, Aleven, McLaren, \& Koedinger, 2007). Students of seeking-help group frequently referred to the intelligent autotutor's feedback and this lead them to be less autonomous learners than self-monitoring group learners. Intelligent tutoring systems present various structures to support students' learning. One such structure which investigated in this research is immediate corrective feedback. It is revealed that this simple support presented by an intelligent tutoring system during completing the task improved students' learning significantly in comparison to traditional method which did not present any immediate corrective feedback. However, research has indicated that most of learners do not efficiently benefit from these traits. Aleven and his colleagues (2003) explored ineffective help use in interactive learning settings and they asserted that system-related factors, student-related factors and interactions between these factors, affect seeking-help behaviours. It is revealed that there were learners who contrary to instructing in the same conditions did not efficiently benefit from them and accordingly did not promoted in their learning process. This has led in wheel spinning phenomenon in which learners insisted without significant promotion in their learning process.

Applying SRL via intelligent tutoring system in speaking has some advantages. The first advantage is agency. When there is a necessity to regulate students' performance, SRL approach motivates learners to suppose ownership for their learning procedure (Aleven, Stahl, Schworm, Fischer, \&Wallace, 2003). For instance, Walker and his colleagues (2010) studied on peer-tutoring setting in which learners assist each other to complete the task. Instead of explaining the conversation process for the learner, the intelligent tutoring system proposed prompts and hints without constraining them. A second advantage of SRL through intelligent tutoring system is that students engage in practicing key self-regulatory strategies. By providing conditions for learners to regulate their performance, learners engage in practicing key SRL strategies, and receive appropriate immediate feedback (Corbett \& Anderson, 2001). In general, providing immediate feedback to the students does not allow them to recognize and assess their own mistakes. Thus, allowing students to involve in procedures of error recognition and receiving immediate feedback, may improve both their domain-level knowledge and their application of self-monitoring strategies (Mathan \& Koedinger, 2005). Other advantages of the SRL via intelligent tutoring system, as revealed by the results of the questionnaire, are well organization of the course content, easiness of it's application and it's capability to allow students learn at their own style. On the other hand, the main weakness of intelligent tutoring system is its incapability to hold learner-learner and learner-teacher conversations during learning process. In general, the majority of studies (Leelawong \& Biswas, 2008; Graesser, 2010; D’ Mello \& Graesser, 2012; and Kosek \& Lison, 2014) confirmed that learning through computer-assisted intelligent tutoring system has significant positive effect on students' learning. 


\section{CONCLUSION}

In general, the current study suggests that SRL through intelligent tutoring system enhances students' performance in speaking. In this study, before applying SRL through intelligent tutoring system, the students of the experimental groups obtained lower scores on speaking test. However, after the implementation of SRL through intelligent tutoring system, the SRL groups performed significantly in their speaking tests. The semester long assessment study has appeared the strengths and weaknesses of the intelligent tutoring system. It also paved the way for future studies. Some advantages of the intelligent tutoring system over the traditional teaching method in learning speaking have mentioned. Students who learned through intelligent tutoring system asserted that the system assisted them to learn effectively. They were also satisfied with the intelligent tutoring system's capability to support them with much appropriate corrective feedback, prompts and hints for completing the task. The psychology field has studied SRL in recent years, which has led to various approaches that can promote education. Some intelligent tutoring systems have incorporated traits to assist learners who lack SRL strategies, like automatically recognizing when a learner is confused and presenting additional support when he/she is failing in completing the task. However, little research has investigated how technology can effectively enhance SRL. By combining vast knowledge of SRL with the features of intelligent tutoring systems, the current study intends to assist learners to improve their speaking ability.

\section{REFERENCES}

Aleven, V., Stahl, E., Schworm, S., Fischer, F., \&Wallace, R.M. (2003). Help seeking and help design in interactive learning environments. Review of Educational Research, 73, 277-320.

Azevedo, R. (2008). The role of self-regulation in learning about science with hypermedia. In D. Robinson \& G.Schraw (Eds.), Recent innovations in educational technology that facilitate student learning (pp. 127-156). Charlotte, NC: Information Age Publishing.

Baker, R. S. J. d. (2007). Modelling and understanding students' off-task behavior in intelligent tutoring systems. In M. B. Rosson \& D. J. Gilmore (Eds.), Proceedings of ACM CHI 2007: Computer-Human Interaction (pp. 1059-1068). New York, NY: AC.

Baker, R., Walonoski, J., Heffernan, N., Roll, I., Corbett, A., \& Koedinger, K. (2008).Why students engage in "gaming the system" behavior in interactive learning environments. Journal of Interactive Learning Research, 19, 185-224.

Butler, R. (1998). Determinants of help seeking: Relations between perceived reasons for classroom help-avoidance and help-seeking behaviours' in an experimental context. Journal of Educational Psychology, 90, 630-643.

Chi, M. T. H., Siler, S. A., Jeong, H., Yamauchi, T., \& Hausmann, R. G. (2001). Learning from human tutoring. Cognitive Science, 25, 471-533. 
Corbett, A. T., \& Anderson, J. R. (2001). Locus of feedback control in computer-based tutoring: Impact on learning rate, achievement and attitudes. In J. Jacko, A. Sears, M. Beaudouin-Lafon \& R. Jacob (Eds.), CHI'2001 conference on human factors in computing systems (pp. 245-252). New York: ACM Press.

D’Mello, S. K., \& Graesser, A. C. (2012). Autotutor and Affective Autotutor: Learning by Talking with a Cognitively and Emotionally Intelligent Computer that Talks Back. ACM Trans. Interactive Intelligent. Syst. X, X, Article XX (Month 2011), X pages.

Good, T., \& Brophy, J. (1995). Contemporary educational psychology. New York: Longman.

Graesser, A.C., Franklin, S., and Wiemer-Hastings, P. and Tutoring Research Group (1998). Simulating smooth tutorial dialog with pedagogical value. Proceedings of the American Association for Artificial Intelligence (pp. 163-167). Menlo Park, CA: AAAI Press.

Graesser, A.C., Wiemer-Hastings, K., Wiemer-Hastings, P., Kreuz, R., and Tutoring Research Group (1999). Autotutor: A simulation of a human tutor. Journal of Cognitive Systems Research, 1, 35-51.

Graesser, A.C., Mary Anne Britt, Keith K. Millis, Patty Wallace, Diane F. Halpern, Zhiqiang Cai, Kris Kopp, Carol Forsyth (2010). Intelligent Tutoring Systems (2), 327329.

Graesser, A.C., \& McNamara, D (2010). Self-Regulated Learning in Learning Environments with Pedagogical Agents That Interact in Natural Language, Educational Psychologist, 45:4, 234-244, DOI: 10.1080/00461520.2010.51593.

Jarvela, S. (2016). How do types of interaction and phases of self-regulated learning set a stage for collaborative engagement?, Learning and Instruction. http://dx.doi.org/10.1016/j.learninstruc.2016.01.005.

Kim, Y., \& Baylor, A. L. (2006). Pedagogical agents as learning companions: The role of Agent competency and type of interaction. Educational Technology Research \& Development, 54(03), 223-243.

Kistner, S., Rakoczy, K., \& Otto, B. (2010). Promotion of self-regulated learning in classrooms: Investigating frequency, quality, and consequences for student performance.

Kizilcec R.F., Pérez-Sanagustín M., \& Maldonado J. J. (2016). Self-regulated learning strategies predict learner behavior and goal attainment in Massive Open Online Courses, Computers \& Education, doi: 10.1016/j.compedu.2016.10.001.

Koedinger, K. R., Suthers, D. D., \& Forbus, K. D. (1999). Component based construction of a science learning space. International Journal of Artificial Intelligence in Education, 10, 166-175.

Koedinger, K. R., \& Aleven V. (2007). Exploring the assistance dilemma in experiments with Cognitive Tutors. Educational Psychology Review, 19,239-264. 
Koedinger, K. R., Aleven, V., Roll, I., \& Baker, R. (2009). In vivo experiments on whether supporting metacognition in intelligent tutoring systems yields robust learning. In D. J. Hacker, J. Dunlosky, \& J.C.Graesser, A.C. (eds.) Handbook of Metacognition in Education, pp.897-964.Routledge, New York.

Kosek, M., \& Lison, P. (2014). An intelligent tutoring system for learning Chinese with a cognitive model of the learner. In (S. Jager, L. Bradley, E. J. Meima, \& S. Thouësny Eds), CALL Design: Principles and Practice; Proceedings of the 2014 EUROCALL Conference, Groningen, The Netherlands (pp. 179-184).Dublin: Researchpublishing.net. doi:10.14705/rpnet.2014.000214.

Leelawong1, K., \& Biswas, G (2008). Designing learning by teaching agents, the Betty's Brain System. Department of EECS/ISIS, Box 351824, Station B, Vanderbilt University.

Mathan, S. A., \& Koedinger, K. R. (2005) Fostering the Intelligent Novice: Learning from errors with metacognitive tutoring. Educational Psychologist. 40(4), 257-26.

Roll, I., Aleven, V., McLaren, B., \& Koedinger, K. (2007). Designing for metacognition applying Cognitive Tutor principles to metacognitive tutoring. Metacognition and Learning, 2, 125-140.

Ryan, A. M., Pintrich, P. R., \& Midgley, C. (2001). Avoiding seeking help in the classroom: Who and why? Educational Psychology Review, 13, 93-114. Metacognition and Learning, 5 (2), 157-171.

Shih, B., Koedinger, K. R., \& Scheines, R. (2008). A response time model for bottomout hints as worked examples. In R. S. J. d. Baker, T. Barnes,\& J. Beck (Eds.), Educational Data Mining 2008: 1st International Conference on Educational Data Mini Proceedings (pp. 117-126).Montreal, Quebec, Canada.

Walker, E., Walker, S., Rummel, N., \& Koedinger, K. R. (2010). Using problemsolving context to assess help quality in computer-mediated peer tutoring. In $\mathrm{V}$. Aleven, J. Kay, \& J. Mostow (Eds.), Proceedings of the 10th International Conference on Intelligent Tutoring Systems, ITS 2010 (Vol. I, pp. 145-155). Berlin, Germany: Springer.

Winne, P., \& Hadwin, A. (2008). The weave of motivation and self-regulated learning. In D. Schunk \& B. Zimmerman (Eds.), Motivation and self-regulated learning: Theory, research, and applications (pp.297-314). Mahwah, NJ: Erlbaum.

Zimmerman, B. (2000). Attaining self-regulation: A social cognitive perspective. In M. Boekaerts, P.R. Pintrich, \& M. Zeidner (Eds.), Handbook of self-regulation (pp. 13-70). San Diego, CA: Academic Press.

Zimmerman, B., \& Schunk, D. (2001), Reflections on theories of self-regulated learning and academic achievement, In Zimmerman B. and Schunk D., (Eds.), Self-Regulated Learning an Academic Achievement, Theoretical Perspectives (2nd Ed.), Mahwah, NJ, Erlbaum 2001, pp. 289-307. 
Zimmerman, B. (2008). Investigating self-regulation and motivation: Historical background, methodological developments, and future prospects. American Educational Research Journal, 45(1), 166-83. 